\title{
Scaling Techno-Optimistic Visions
}

\author{
SEYRAM AVLE \\ UNIVERSITY OF MASSACHUSETTS, AMHERST \\ CINDY LIN \\ UNIVERSITY OF MICHIGAN \\ JEAN HARDY ${ }^{3}$ \\ UNIVERSITY OF MICHIGAN \\ SILVIA LINDTNER \\ UNIVERSITY OF MICHIGAN
}

\begin{abstract}
Techno-optimism, or the enduring belief that technology use and production are promising for humanity, is bound up in past and ongoing ideals of modernity, progress, and "development." As a particular form of hope and aspiration, techno-optimism is harnessed for nation-building and economic development projects that invest in the promise of scaling. This article demonstrates that this enduring techno-optimism requires various forms of entrepreneurial labor, and that the promise of scaling and technological progress together form a contemporary technique of governance.
\end{abstract}

\section{Keywords}

digital technology; entrepreneurial life; entrepreneurial citizens; technological promise; scale; techno-optimism

\section{Introduction}

From the 1990s through to the early 2000s, digital technologies were seen as empowering individuals to participate in political debate and decision making, be it the ideas of a "creative class" or the promise of social media's revolutionary and networked capacities (Castells 2011;

Seyram Avle, Email: savle@umass.edu 'Cindy Lin, Email: cindylky@umich.edu sean Hardy, Email: jkhardy@umich.edu Silvia Lindtner, Email: lindtner@umich.edu 
Florida 2014). Educational tech initiatives continue to be framed as promising alternatives to "old" hierarchies and bureaucracies, despite the various forms of exclusion along racial, class, gender, and other lines they reproduce (Ames 2020; Bivens and Haimson 2016; Fox et al. 2017; Sims 2017). Techno-optimism, or the enduring belief that technology use and production are promising for humanity, is bound up in past and ongoing beliefs in modernity and "development" (Ferguson 1990). As a form of hope and aspiration, techno-optimism is harnessed for nation building through scale making and often requires "venture labor" (Neff 20120), the exploitation of "entrepreneurial citizens" (Irani 2015; 2019) and of "happiness workers" who labor to sustain the belief in techno-optimism (Lindtner 2020).

We show that techno-optimism has become deeply intertwined with the promise of scale and scale making as techniques of governance. Specifically, we unpack how techno-optimism endures in a variety of nation building projects of regions (formerly) labeled the tech periphery (Chan 2014): China, Ghana, and Indonesia. We zoom in on efforts that render digital technologies integral to national futures, and show how scale is used as a logic for action in favor of long-held aspirations for alternative modernities. We use scale both i) as an analytic tool, i.e., by attending to scale making endeavors, and ii) as an object of inquiry, i.e., by examining how scale is deployed by certain actors. This follows a line of STS and cultural anthropology scholarship (Hecht 2018; Tsing 2011; Carr and Lempert 2016; Latour 2005) that conceptualizes scale both as a "category of analysis and a category of practice" (Hecht 2018, 111). This study of scale making aligns with work in STS and anthropology that questions assumptions of scale by opening up entrenched and seemingly universal categories such as "the global" and "neoliberalism" (Carr and Lempert 2016; Hecht 2018; Ong 2006; Tsing 2011, 2015; Zhang 2014). Specifically, we are "attending to the pragmatics of scale" (Carr and Lempert 2016) by studying techno-optimism as a scale making practice; in other words, we examine how techno-optimism is sustained through specific social, cultural, and technopolitical processes.

We draw from ethnographic research in Ghana, Indonesia, and China where we have studied how technological promise persists via the set-up of innovation hubs, incubators, makerspaces, educational programs, policies, urban redesign, land mapping, and urban upgrade. Spanning a decade in China (2008-2018 - Lindtner), seven years in Ghana (2011-2018 - Avle), and three in Indonesia (2015-2018 - Lin), this research has focused on the social, cultural, and material processes of technological production and use. We worked with tech entrepreneurs, designers, manufacturing firms, government bureaucrats, environmentalists, earth scientists, urban planners, and policy makers across various locations and networks. We conducted observations at public and semi-public events and gatherings, including but not limited to hackathons, startup weekends, Maker Faires, pitch competitions, and trade fairs. Throughout our collaboration, we read these sites and their aspirations in relation to one another to understand how technological promises are simultaneously shared and differ in their manifestations. We "followed" the promises of digital technologies and the practices that sought to bring them to life across these different sites, with the understanding that culture and society are made and not given. Our multi-sited approach underscores the importance of multiple meanings and lived realities (Falzon 2009; Ong and Nonini 2003; Appadurai 1996; Marcus 1995; Massey 1993). For this article, 
we bring our findings together given 1) the transnational frictions and relations of shared expertise, capital, and labor we observed across and between our sites, 2) the central role that hope and aspirations for alternative futures play in contemporary technology practice and

discourse, and 3) various forms of labor that people are frequently required to undertake for the purpose of realizing techno-optimistic visions.

We demonstrate that techno-optimism lives on-albeit in ambivalent and contradictory ways--through tech entrepreneurial training projects in Ghana, land mapping for future carbon markets in Indonesia, and in aspirations to scale technological promise in China. National visions encompass, among other things, imagined, ideological, and affective attachments to particular places (Anderson 1991; Tuan 1975). We show that contemporary nation building projects enroll techno-optimism by deploying scale as a logic for action, and how, in this process, technooptimism and scale are bound together as techniques of governance.

\section{Attending to the Pragmatics of Scale}

Prior work in STS and anthropology has variously cautioned against assuming pre-fixed scales to phenomena (Carr and Lempert 2016; Lempert 2012; Latour 2005; Gal 2016; Haraway 1998; Hecht 2018; Knorr Cetina 2009; Tsing 2012;). That is, rather than adhere to seemingly normative scales or take for granted existing scalar differentiations like micro vs. macro, these scholars advocate for seeing scales and scale-making as sociomaterial phenomena. Attending to the pragmatics of scale is to do three things. First, it is to resist the urge to rely on predefined categories, especially the ones afforded by the promises of digital technology, as ontologically given, and, rather, to carefully uncover the ways that scales are made (Carr and Lempert 2016; Hecht 2018; Irvine 2016). For instance, rather than conclude that Silicon Valley investors reward scale in general, we might probe exactly which kinds of projects are seen as promising to "scale up" over others. The scalar impact of digital technology assigns weighty significance to technological progress, prosperity, and development, so much so that scale itself is seen as inevitable. And doing so also takes scale, its relationship to techno-optimism, and its impacts for granted.

Second, a pragmatics of scale means attending to practices of scaling and how temporal, spatial, and ideological hierarchies and relations are produced. As Carr and Lempert explain, scaling is often about creating hierarchies and assigning "value and weight to both real and abstract things, in ways that for instance, is demonstrated in how people imagine the nation state to "hover 'above' communities" (p. 3). This tends to elevate nation state goals over individuals' needs and aspirations, with minority groups often subsumed or silenced.

Third, it means close attention to the claims and reasonings actors make about their position(ing), comparisons, and categories reveal or hide ways that they orient their social world (Carr and Lempert 2016; Hecht 2018; Tsing 2000, 2011, 2012, 2015). This is particularly important where techno-optimistic claims are being made on behalf of others-whether it is by a government, intergovernmental organization such as the UN, humanitarian organizations, academics, the tech industry, and so on. By attending to how various actors make claims, a 
pragmatics of scale assists in locating what is at stake, who benefits or loses, as well as the consequences in the contexts in which they are deployed.

In what follows, we focus specifically on how techno-optimistic visions are deployed to intervene at the scale of the nation. We show that this process is sustained through various forms of labor that nurtures a promising technological and "entrepreneurial life" (Lindtner 2020). We also show how people are called upon to invest their hopes and channel regional histories as "difference" for the purposes of nation building (Irani 2019) and of experimenting with what constitutes the nation (Lindtner 2020). Scale is used in these cases as a galvanizing logic through which techno-optimism becomes embedded into governance structures and public discourse. In other words, scale making helps align various hopes and aspirations with the goal of national upliftment.

Kaushik Sunder Rajan (2006) shows that technoscience and commercial capital are deeply intertwined in processes of valuation and commodity circulation. Similarly, we unpack how the labor of sustaining techno-optimism and technological promise is shaped by the interests of finance capital, the promise of technological experimentation and value accumulation. We demonstrate that these attachments of techno-optimism to capital, experimentation, and accumulation require the labor of aligning people's dreams with state interests. Scalar projects do not just happen; they require specific labor and exploit pre-existing "topographies of power" (Ferguson 2014) and "power geometries" (Massey 1993). By taking a pragmatics of scale approach, we unpack how entrepreneurial dreams and hopes for liberation are exploited for the sustaining of powerful technopolitical projects (Hecht 2012, 2018).

\section{Hacking Economies of Scale in Shenzhen}

In a 2015 Kickstarter campaign, the open source hardware producer Seeed Studio promoted one of its latest products--the DIY (Do-It-Yourself) cell phone kit "RePhone"--as follows: "What if we designed a phone to be anything we want it to be? For the last eight years in Shenzhen, Seeed Studio has been busy hacking the electronics supply chain, to make advanced tools and technologies available to everyone. The result is the RePhone." The 2015 crowdfunding campaign for an assemble-your-own mobile phone kit neatly summarized the ambitions that had brought together a loose collective of open source hardware and maker advocates active in China since 2007. Alongside broader uptakes of ideals of open source hardware and making in the United States around the 2007-08 financial crisis, China's maker advocates had begun to position Shenzhen, a city in the south of China, as an ideal region to "scale" open source hardware and entrepreneurial initiatives from prototyping and hobbyist tinkering into mass production. While open source hardware platforms, like the Arduino, promised to enable people without a professional engineering degree to open up the black box of everyday electronics and endconsumer devices, an engagement with Shenzhen promised to teach about the inner workings of global trade, supply chain networks, and mass production. It promised to open up the black box of "economies of scale." 
Seeed Studio began as a small business in 2008, but quickly made a name for itself amongst American and European maker and open source hardware advocates. By 2012, the company's promise to allow many others to "hack" technology at scale had allowed the company itself to "scale." With 95\% of its product sales stemming from the European and American opensource hardware markets, it had turned into a \$15 Million USD revenue business, with over 100 employees. Over the years that followed, a growing number of maker-entrepreneurs would travel to Shenzhen to see and experiment with scale themselves. Seeed Studio offered free factory tours and organized visits to the city's electronics markets. It produced maps of the region to help foreign makers and start-ups "see" the vast landscape of industrial production and hosted Maker Faires and other events to demonstrate how one "hacked global supply chains" in practice.

A series of foreign (largely Western) finance and educational exchange programs began investing in this promise of scaling hobbyist tinkering and entrepreneurial making into product development. In 2014, prominent Western tech media picked up on the stories that maker advocates had been proliferating over the years prior: they portrayed and celebrated Shenzhen as a rising hub of innovation, as "a Hollywood for Makers" and the "Silicon Valley of Hardware." According to these accounts, Shenzhen had seemingly overnight turned from a region known for its low-quality production and industrial excess into an innovation powerhouse. These stories portrayed Shenzhen as newly emergent, rebuilt and remade by the ideals and tools familiar to Western IT innovation hubs: finance capital, start-up culture, and ideals of participation and open sharing. Such stories of newness, successful transformation, and the promise of intervening at scale attached to Shenzhen rendered invisible the region's other stories and histories of scale making.

Following a scalar technique of analysis means traveling between both spatial and temporal scales. As Carr and Lempert write: "Scaling ... may organize not only spatial relations but spatio-temporal ones as well. Indeed, when one tries to apprehend things and their qualities, a present moment may be linked to and authorized by a moment figured far back or projected forward in time. In order to determine when and where we are, we may evoke a grand continuity, if not an evolution" $(2016,2)$. Though seldom specifically addressed in maker discourse, promise of scaling in Shenzhen is linked to the 1980s, when China was experimenting with its transition into a post-socialist market economy. In 1979, Chairman Deng Xiaoping declared a plot of land just north of Hong Kong a Special Economic Zone (SEZ): Shenzhen. As an SEZ, Shenzhen became one of the first regions in China that allowed foreign-direct investment, entrepreneurial activity, experimentation with non-socialist models of urban living and working, and capitalist market activities. In the 1990s, Shenzhen was declared a success and a model for China as a whole (Cartier 2002; Gallagher 2007; O'Donnell et al. 2017), eventually "breeding promiscuously with other enclave formats, or "parks," merging with offshore financial areas, tourist compounds, knowledge villages, high technology campuses, museums, and universities" (Easterling 2012).

Shenzhen's history of experimentation with urban form, statecraft, and political economy centrally shapes the region's contemporary allure in the West (see Lindtner 2020 for details). Designers, engineers, investors, educators, and even politicians and policy makers from abroad 
have endorsed Shenzhen as a model for turning "outdated" infrastructures from industrial production to city management into a renewed "regional advantage" (Saxenian 1996). Seldom is this through the investment into new infrastructure development. Instead, existing spaces are "upgraded" into incubator spaces, fablabs, and other mini-zones from innovation hubs to creative parks. Such upgrades require relatively little financial investment as they run on the entrepreneurial agility and free labor of passionate participants (Terranova 2000). Shenzhen's history is rendered invisible in part because many of the European and American designers and engineers turned their attention towards China in the years following the financial crisis 2007-08, a time when their own fields and industries were being experienced and debated as highly precarious. Shenzhen offered to redeem technological promise and future making at a moment when earlier visions of a global information society and stories of individual empowerment were more widely critiqued (Lindtner 2020).

In contrast, China's maker advocates were seldom able to mobilize articulations of techno-optimism (now attached to Shenzhen) in the same way. European and American maker advocates celebrated the region's history and continuous practice of illicit experimentation and grey market electronics production as carrying promise, because they saw it as an alternative to Western corporate IT culture and capitalist structures more broadly. Their Chinese counterparts, however, hoped to disassociate from the region's informal production culture that had garnered so much international attention. For them, Shenzhen's grey market electronics production and its associations with copycat and fake was precisely what was holding China back from being taken seriously (by the West) as an authentic site of modernity and partner in design and innovation.

The people who set up China's early open source hardware spaces and projects with which this section began expressed ambivalence towards the uptakes of their ideals. In their early work, they often struggled to dispel common Western images of China as lagging behind, copycat, and fake. For instance, when Seeed Studio gained popularity in 2010, Eric Pan (the founder) was invited to attend the Open Source Hardware Summit in New York City. There, he found many people who knew about his company but did not realize it was a Chinese company. "None of them believed that innovative products could come out of a Chinese company," he said during an interview with me [Lindtner] in 2013. Only after Pan returned from the conference in NYC did the company begin to advocate more explicitly a view of China that challenged inherent associations with fake and low-quality production.

While Western tech corporations, investors, policy makers, and open source hardware advocates turned to Shenzhen as hopeful and promising because it evidenced the fissures and gaps of technological progress, economies of scale, and globalized capitalist production, China's maker advocates yearned for China to be granted-at last-the status of modernity. This yearning for modernity among Chinese maker advocates has complicated roots in colonial history and weaves throughout China's socialist and post-socialist eras (Anagnost 1997; Wallis 2013). Under Mao Zedong, for instance, socialism was rendered as a project of modernity that enabled China to position itself not behind but in advance of a decaying Europe (Dirlik 1989). Modernity, here, was to be achieved via class struggle and the transformation of the self into revolutionary subjects. In the 1980s post-socialism, the Chinese government attributed China's 
failure to modernize to the "low quality" of its people, used as a general explanation for everything that held the Chinese nation back from achieving its rightful place in the world lost during the period of "national humiliation," i.e. the Opium Wars and European Colonialism in the late 19th century (Anagnost 1997; Greenhalgh 2010; Rofel 2007). More recently, particularly in $\mathrm{Xi}$ Jinping's era, the entrepreneurial maker is positioned as a new model citizen to enable China to reposition itself amidst economic slow-down in a global economy of finance speculation and trade disputes.

China's histories of partial colonization by the West and the yearnings for modernity they induced live on in the allure of hacking economies of scale in Shenzhen. They lurk in the quest to open up the black box of "economies of scale" through Shenzhen even as claims that China may still be lagging behind, still not quite caught up with the West, continue on. It is the endurance of these colonial pasts in contemporary technology production that centrally shapes the scaling and rescaling of techno-optimistic visions.

\section{Scaling Tech-entrepreneurial Desires in Ghana}

Tech incubators, accelerators, and hubs evince the techno-optimism underlying urban and economic renewal projects around the world. In Ghana's cities, tech entrepreneurial hubs have become popular sites for people interested in making software and hardware to co-work, participate in pitches, run hackathons, and generally hang out. Most of these hubs were founded by young middle-class people who, according to one of them, "started this as a passion with no experience." Between 2008 and 2017, the number of hubs in Ghana increased from 2 to 16, covering most of Ghana's administrative regions. For hub founders, rendering hubs visible was their contribution to building a tech industry that would contribute to shaping Ghana's economy. By making hubs the locus of youthful tech entrepreneurial activity, they hoped to set Ghana on a path towards a stronger and better technological future imagined to be filled with technological innovations that served the country's population. Built largely outside state intervention, those who used these hubs described them as spaces to cultivate and contribute to a more hopeful future for their country.

In 2016, Ghana's government elections were met with a cautiously optimistic attitude by the local tech scene. Deemed technocrats, these were the kinds of people who seemed to share similar (neoliberal) ideas and visions for Ghana's tech future to those of hub founders, especially in contrast to the previous government which was perceived by many Ghanaian entrepreneurs and people in tech industry as bureaucratic. Much of the new policy talking points seemed to confirm the hub founders' perception that there might be an opportunity to work with the government for the first time. For instance, there was the creation of two new ministries that seemed aligned with the hubs' interests: a Ministry of Environment, Science, and Technology (MESTI) and a Business Development Ministry. The lead ministers and the staff of these new ministries routinely attended events that included hub members, making visible overlapping interests in digital technologies and entrepreneurship. An ambitious "One District, One Factory" policy was later initiated, aimed towards moving the country away from primarily exporting raw 
materials towards adding value through industrial processing and manufacturing. All these administrative moves fed into a pithy policy statement, "Ghana Beyond Aid," which was often repeated by government ministers. "Ghana Beyond Aid" referenced a desired move from dependence on foreign aid and rested on the nation's postcolonial history of relying on institutions like the World Bank and the IMF, as well as western governments, to generate capital through grants and loans.

Ghana's primary export focused economy was partly an outcome of its participation in a colonial governance and economic strategy that fed Britain's industrial revolution with raw materials from its colonies. Since independence in 1957, successive Ghanaian governments have tried to shift the new nation's fortunes away from this colonial legacy, even though, as Collier (2011) has shown, often the new elites stood to benefit from maintaining the very systems whose purported dismantling brought them to power in the first place. For the Ghanaian government, circa 2016, entrepreneurship was a key thread in all this, with ministers proclaiming that for Ghana to move to the next level everyone had to be entrepreneurial. They spelled out entrepreneurial citizenship (Irani 2015, 2019) through business activities and tech driven ambitions as a shared burden for Ghana's "development." To that end, the government created a National Entrepreneurship and Innovation Plan (NEIP) to "enable new businesses to emerge and give them the space to grow, to receive financing and business development services, to secure orders during the critical formative years, and to tap into a wide supply chain and network for their growth years, helping to create jobs at a widely distributed national level" (NEIP.gov.gh 2018).

In August 2017, the founders and managers of 15 of the 16 hubs at the time came together to formally register an entity called the Tech and Business Hubs Network (TBHN), renamed in 2019 as the Ghana Hubs Network. The goal was to provide a united face to lobby the government and become more visible to the general public. By creating a legal organization with members all over the country, they believed, they could "scale up" their activities in ways that each individual hub by itself could not. An organization with members drawn from across the country could argue for "national" projects and claim "national" impact as well. Achieving legibility en route to this future scale meant particular labors and material efforts to align operations of individual hubs into a coherent whole. At the time, I [Avle] followed several in-person meetings and hundreds of group text messaging on WhatsApp, where people shared their experiences of lobbying and fundraising, where they planned annual meetings, and synthesized various programs so that they became complementary. All of these activities produced a powerful narrative about the potential of investment in technology impact and entrepreneurial support.

Once formalized, the Hubs Network actively lobbied the government, arguing that the new ministries and policy programs perfectly aligned with the Hubs Network's goals for the country. In particular, the NEIP's mandate included an incubation and accelerator program, something the hubs were already doing and could implement efficiently. They convinced the government that NEIP's success would also require training young people to become entrepreneurs and learn to use digital tools. Because of rapid technological change, they argued, the government needed to add digital technology skills to business training programs, if NEIP 
was to achieve its goal of developing a nation of tech-savvy entrepreneurial citizens. Using their various programs-for instance coding schools, women focused technology classes, hackathons and pitch contests - and examples of previous governments' efforts at digital training centers and World Bank programs to support their case, they successfully lobbied for adding tech entrepreneurial training to the NEIP's agenda. By April 2018, the training was underway and 7000 Ghanaian youth were in a pipeline to be trained by the Hub Network, according to the appointed director at the time, Jorge Appiah. Through their "collective bargaining effort," as he put it, a generic national entrepreneurship plan had become a national tech entrepreneurship plan with a built-in action plan.

When scalar imaginations align, they can produce infrastructure (Hecht 2018). Here, two parties agreed that a nation-wide entrepreneurial campaign was a necessary project for a desired future of increased economic growth. The new government's technocratic approach in many ways looked and sounded like the Hub Network and its articulated beliefs in the power of entrepreneurship. The very name of the flagship program, "National Entrepreneurship and Innovation Plan," indicated the shared ideas about the role of entrepreneurship and technological innovation. Yet, nowhere in the NEIP's plan at the time did it codify attention to digital technology. Industrialization in the government's narratives was generic and non-specific, and if anything geared toward industrial manufacturing, as suggested by the related "One District, One Factory" policy. The Minister for Environment, Science, Technology, and Innovation often emphasized the importance of machinery and foundry technology in general for economic growth.

While the government endorsed technology entrepreneurship broadly as key to economic progress, the Hub Network promoted digital technology to fit within this broader techno-optimistic view of the future. For the Hub Network, digital technology skills, when scaled nationally, would assure the kind of growth the nation has long sought. The hope was that the state supported program would enable the growth of Ghana's startup ecosystem and the buildup of a "real" tech industry. The Hub Network eventually convinced the government that tech entrepreneurial training programs were crucial for this future to materialize; their visions had "scaled" into a new policy for youth training. In the process, their labor became enrolled in a nation building project that required specific work to align interests in ways that would channel people's hopes for the government's own (broad) techno-optimistic visions. This process of alignment required letting go of some individual plans and dreams so that hub activities could be scaled "nationally." People set aside individual negative feelings about the state apparatus in order to realize this national vision. The scale that both the network and the government evoke, i.e., the national, "collapses and remakes" (Gal 2016) alliances to enable nation building.

\section{Scalar Visions of Indonesia's Forests}

In 2011, the Indonesian government instituted the One Map Policy to generate a "super databank" of forest maps across the country's 18,309 islands. The aim of the policy was to render attractive Indonesia's forest land for carbon financing, against the backdrop of recent state and 
public interest initiatives for spatial data transparency. Mapping methodologies and technologies were positioned as enabling Indonesia's participation in a global climate initiative called REDD+ (Reducing Emissions from Deforestation and Forest Degradation Plus), an instrument and measure that finances a country's efforts in forest conservation. REDD+ was geared at tackling global climate change by reducing emissions from deforestation and the Indonesian government aspired to be at the forefront of such efforts. The purpose of REDD+, and its relationship with One Map, was to prevent plausible events that lead to forest clearing. The One Map Policy stipulated that forest clearing must be documented (visualized) and updated in real-time, promising certainty to its viewers. In the process of implementing One Map Policy, state agencies produced a series of conflicting maps that obfuscated the exact location and remaining quantity of forests.

Doubts and uncertainty over Indonesia's forest records have existed for decades. As geographer Jenny Goldstein (2014) notes, many international agencies discredit "developing" countries' historical national inventories and land cover databases, making it difficult to set baselines for measuring forest loss. It is this longer history of (often) Western stipulations of Indonesia lacking accuracy in land mapping that pushed the government to adopt a series of remote sensing and international satellite techniques that promised to produce "accurate" data. In order to account for ongoing changes in forest land, the National Mapping Agency, together with Indonesia's Ministry of Forestry and Environment, remapped forest boundaries with remote sensing technologies so that public and private investments could be made with certainty. Delineating clear boundaries, however, proved difficult due to the country's histories of resource exploitation administered across decentralized political units. From 1998 onward, Indonesia's timber industry, a critical portion of Indonesia's economy, has become increasingly decentralized and privatized. The resulting informal land grabs have made official records of land ownership-and therefore resource extraction and trade- difficult to track. Furthermore, the high cost of satellite imagery and field surveys meant that ministries prioritized the mapping of areas designated for plantation development over others, which is a source of controversy for public interest groups interested in conservation and the land rights of ethnic minorities. All of this led to the production of multiple and contradictory maps with forest boundaries that do not match up. It is in this set of sociotechnical arrangements-high data production cost and a decentralized resource economy-and aspirations for credible data that drones became a solution for producing imagery of the nation's forest at scale.

When One Map Policy was announced, a group of environmental activists and technologists at the grassroots initiative School of Drones made it their task to "truly" implement the policy's underlying aspiration to produce accurate images of deforestation with DIY aerial drones. Using DIY and low-budget drone technology, they hoped to directly support citizen claims to land against misappropriation by corporate and often illegal resource extraction activity. The Indonesian government considered drone imagery as potential contributions to President Joko Widodo's (2016) decree for the acceleration of One Map Policy in 2016. Drone imagery was positioned as an opportunity to lower production cost and speed up ground checks of illegal deforestation, exactly because DIY drones promised to produce images for land use 
mapping within a day or two, unlike state-administered maps that take more than six months for approval and publishing. In other words, while School of Drones saw their "counter maps" as a tool for justice, the Widodo government framed them as further legitimizing and potentially accelerating One Map Policy.

In 2015 the School of Drones team assembled a drone to produce a high-resolution map of a bauxite mining concession that shared overlaps with a community's land claims in Borneo. The mining company in question had drained a lake, which had previously been vital to the community for subsistence fishing (Radjawali and Pye 2015). By processing recently taken aerial photographs and then overlaying the images on the official concession map (creating "orthophotos"), School of Drones provided proof that the mining company was illegally operating outside its concession boundary. These drone images, according to School of Drones, convinced viewers of what they see, and this is crucial for its legitimacy and visibility in legal realms. Orthophotos were accepted as evidence of detrimental environmental effects of mining by the Constitutional Court of Indonesia Borneo for the first time in 2015 (Radjawali and Pye 2015). Orthophotos seemed to demonstrate that high-resolution drone imagery could provide reliable evidence of illegal deforestation. Instead of colored blocks or shaded areas typical of forestry maps, these images offered fine-grained pixels of forests exposed to open-cut mining. Drone flight routes were seen as offering accurate modes of witnessing resource exploitation. Drone flight coordinates became manifestations of lived experiences (Lin and Moon 2016) through the images they produced and they oriented communal ways of "seeing and standing in the world" (Carr and Lempert 2016, 10) in order to make legal instruments that are leveraged for claim making. Drone images thereby functioned as instruments for political claims to expropriated land and worked to reject corporate interest claims.

Despite their somewhat adversarial position, School of Drones members were often called upon by forestry and forestry-related officials in Jakarta, without any compensation or social security, to "drone here, drone there." More often than not, officials presented maps and data by School of Drones as authored by them, without granting authorship rights to School of Drones. These forestry bureaucrats put School of Drones into unofficial service for the state, asking that they fill in their knowledge gaps. The School of Drones, while aware that their precarity entailed misrecognition, inadequate welfare, and salary from the state, still believed their remote sensing method could help delineate forest boundaries and thus achieve justice for Indonesians. As one of them put it, "If no one else does it, who will?"

In late 2017, the Indonesian administration placed One Map Policy under the imperatives of One Data Indonesia. The stated goals of One Data were similar to the original One Map Policy, but renewed emphasis was placed on accurate data as key to public services and effective policy making. Writing in The Jakarta Post, Yanuar Nugroho, a government official at the Executive Office of the President, asked, "How can we have a proper development strategy or accurate policymaking with the absence of single-referenced, precise and reliable data - be they statistical, spatial, and administrative?" Accurate maps, statistics, and technical expertise, here, are positioned as enabling targeted and immediate action and the efficient delivery of policy goals. During the public launch of the One Map GeoPortal in December 2018, President Joko Widodo 
emphasized that "development can be more accurately planned, not only based on data, but also based on the map." This techno-optimistic vision rooted in the promise of accuracy and data masks the labor of experimentation as well as the negotiations between DIY makers and state workers that were necessary to produce this appearance of One Map and One Data. Together the various maps all worked to make claims towards forest land ownership and future valuation in service of a "better" future for Indonesians. Whereas the state aimed to produce accurate maps to attract climate financing at an international scale, School of Drones hoped to create just investments in land to empower people, whom the state had abandoned in its quest for a particular kind of techno-optimistic future. Attending to a pragmatics of scale makes visible how affective investments in technical remedies shaped both state and DIY efforts, but certainly did not empower everyone equally.

\section{Enduring Techno-optimistic Visions}

Since its inception STS has been concerned with the study of how particular things, infrastructures, and systems endure in their sociomaterial and technopolitical forms. From the early social construction of technology project that showed how particular technologies stabilize through social negotiations and "technological frames" (Bijker et al. 1987; Bijker 1997), to a variety of analytical projects, including but not limited to "inscription devices," "market devices," and the study of quantification and infrastructure (e.g. Star and Ruhleder 1996; Roitman 2005; Latour 2005; Hecht 2012; Mitchell 2002, Edwards 1997; Callon 1998; Porter 1996), STS scholars have been committed to unpacking how seemingly natural and taken-for-granted social, technological, and economic structures come into being. An underlying goal of this work has been to unmask the otherwise often hidden workings of power and exclusion. By showing how structures of power are produced, this work is committed to thinking and making existing worlds otherwise (Haraway 1991, 2008).

In line with these commitments, we have shown how techno-optimistic visions are scaled in a variety of places for the purposes of nation making. This scaling of techno-optimistic visions, we have demonstrated, rests on various forms of labor. We have shown, for instance, how techno-optimist ideals live on via the promise of hacking at scale in China, how tech entrepreneurial training programs economize aspirations to uplift Ghana, and how drones are imbued with the promise of future carbon markets in Indonesia. Techno-optimism endures, we argue, because it mobilizes often distinct hopes and aspirations (Ferguson 2006; Irvin 2016; Hecht 2018). Scale, as Hecht reminds us, is "not just about size or granularity. It is also about categories: what they reveal or hide, the ways in which they do (or do not) nest. And it is about orientation: how we position ourselves, what we position ourselves against, and what comparisons such locations do (or do not) authorize" $(2018,33)$. The people we worked with in our research variously oriented themselves to one another and to external forces of global capitalism. These orientations are shaped by longstanding and often ambivalent desires for modernity, progress, and economic growth. School of Drone called on a desire for justice for the disenfranchised to position their work as advocates. The Hub Network in Ghana sought to inject middle class hopes 
and aspirations into government infrastructure to move the nation into more productive sectors of global supply chains. Chinese makers and hardware advocates yearned to repositioning China as freed from its colonial pasts.

The neoliberal state enrolls citizens variously into nation building and economic development programs (Ong 2006). Techno-optimistic visions have become a particularly useful toolkit for such neoliberal techniques of governance. China, Ghana, and Indonesia, alongside other sites of the so-called former tech periphery (Chan 2014), are positioned by state actors and citizens alike as extending and even updating previous techno-optimistic visions. Colonial pasts endure in these displacements of technological promise (Lindtner 2020)

As we have shown, the contemporary allure of Shenzhen in the international tech imagination is shaped by the region's history of capitalist experimentation and postcolonial yearnings for modernization that live on in its institutional and urban infrastructures. Moving our interscalar vehicles in and across such spatiotemporal scales shows how aspirations for being granted modernity as expressed by China's maker advocates today cannot be divorced from histories of colonial encounters and continuous political aspirations to re-assert China's central place in the world, as well as Shenzhen's history of experimentation as an SEZ. Personal and political aspirations to build national and regional futures, here, came together in often contradictory and ambivalent ways. In Ghana, the Hub Network's effort to implement the government's national entrepreneurship plan through a digital tech skills training program rests on the belief that digital technologies offer a new way to train citizens to become better entrepreneurial citizens. By learning to use and create new technologies, the hub network argued, entrepreneurs would be "doubly productive" and solve "real problems." They found kindred spirit in key individuals in the technocratic government, such as a special assistant to the Minister of Science and Technology, as well as the Vice President, who saw digital technologies as special and essential to the larger vision of moving the country away from primary exports and reliance on primary commodity industries. Indonesia's One Map and One Data policies exemplify the state's techno-optimistic outlook on how data and new digital technologies could position the nation in the global carbon trade. Likewise, School of Drones technologists and activists believed their drone mapping techniques could engender effective claims for people who have been historically disenfranchised and displaced by corporate interests. While both the state's aims (through the policy intent) and those of the School of Drones bear the same spirit of improving the lives of people in Indonesia, they are opposed in terms of whose political claims should have precedence. To be able to contest the state at all, School of Drones was paradoxically positioned to aid the government's goals and visions as entrepreneurial citizens providing stateadministered maps and data. One might view their position as untenable, and yet, with few options, they must do both the work of advocating for other, more disenfranchised, citizens while laboring, unpaid, flexible, and precarious, for the administration in order to sustain the legitimacy of the techniques they pioneered and used.

By probing and paying attention to what actors mean when they evoke techno-optimism and what they do when they deploy scale, we point to the ways in which (only particular) forms of entrepreneurial labor were mobilized for national aspirations (while others were continuously 
excluded). Enactments of scale via technology require labor, often unpaid or contributed for free by passionate citizens who want to make a difference. In Indonesia, by producing imagery at a scale that was attractive to the Indonesian government's investment interest, School of Drones managed to insert a compromised vision of forested land into government land use plans. In the Ghana case, a non-state imaginary of socio-economic development was enacted via state action and the entrepreneurial work of the Hub Network resulted in a policy implementation that arguably benefits both the network and the state, albeit less clearly the people who will be enrolled to participate in the training programs. Chinese open hardware advocates labored to reposition and rebrand the nation as freed from colonial tropes of backwards and copycat. In each site, hopes for alternative and more just futures were enrolled into making the nation. This governance "from a distance" was enabled precisely because of the affective and hopeful nature of techno-optimism that binds personal ambition to national techno and capitalist futures and brings them together under the rationalities of state desires to "improve" and "update" society (Irani, 2019; Lindtner 2020; Rose 1990). Scale and techno-optimism are thus bound together as techniques of governance that operate by producing feelings of change and hope for justice.

\section{Author Biographies}

Seyram Avle (she/her) is Assistant Professor of Communication and Global Digital Media at the University of Massachusetts, Amherst. Her research focuses on how digital technologies are designed, produced, distributed, and used in various contexts across parts of Africa, China, and the United States. She is currently working on a book about tech entrepreneurship as a mode of entrepreneurial living and space of work in Ghana.

Cindy Lin (she/her) is a PhD candidate in the School of Information at the University of Michigan, Ann Arbor, and a certificate holder in the Science, Technology, and Society (STS) program. Her research and writing draw on long-term fieldwork with state science agencies, and commercial services firms, to examine the politics of computational labor and data architectures for peatland fire control in Indonesia.

Jean Hardy (he/him) is a PhD Candidate at the University of Michigan School of Information and incoming Assistant Professor at Michigan State University's Department of Media \& Information. His research uses ethnographic and participatory design methods to understand how people use information and communication technologies for community formation and economic development in the rural Midwestern United States.

Silvia Lindtner (she/her) is Associate Professor of Information and Science, Technology, and Society (STS) and the Associate Director of the Center for Ethics, Society, and Computing (ESC) at the University of Michigan. Her first book Prototype Nation: China and the Contested Promise of Innovation (2020) unpacks in ethnographic and historical detail how a growing distrust in Western models of progress, including Silicon Valley and the tech industry after the financial 
crisis 2007-08, shaped the rise of "entrepreneurial living" and the vision of China as a "new frontier" of innovation.

\section{Acknowledgements}

We would like to thank the anonymous reviewers as well as our long-term research collaborators in China, Ghana, Indonesia, and the United States. Conversations and exchanges with the participants at the 2017 NSF workshop Neoliberal Fever have greatly enriched our analytical work: Jeffrey Bardzell, Paul Dourish, Victoria Hattam, Leah Horgan, Steve Jackson, Michelle Murphy, Gina Neff, Holly Okonkwo, Andrew Schrock, Stefanie Steinhardt, Alex Taylor. The research that has informed this article has been in part supported by funding from the National Science Foundation (NSF) under awards \#1513596, \#1617898, \#1901171, \#1744359 as well as the Dow Sustainability Fellows Program, the University of Michigan Rackham International Research Awards Program, and the International Institute Fellowship Program at the University of Michigan.

\section{References}

Ames, Morgan G. 2020. The Charisma Machine: The Life, Death, and Legacy of One Laptop per Child. Cambridge, MA. MIT Press.

Anagnost, Ann. 1997. National past-times: Narrative, representation, and power in modern China. Durham, NC. Duke University Press.

Anderson, B. 1991. Imagined Communities: Reflections on the Origin and Spread of Nationalism. Revised Edition. London and New York: Verso.

Appadurai, A. 1996. Modernity at Large, University of Minnesota Press.

Avle, Seyram, and Silvia Lindtner. 2016. "Design(ing) 'Here' and 'There': Tech Entrepreneurs, Global Markets, and Reflexivity in Design Processes." In Proceedings of the 2016 ACM Conference on Human Factors in Computing Systems, pp. 2233-2245.

Avle, Seyram, Silvia Lindtner, and Kaiton Williams. 2017. "How methods make designers." In Proceedings of the 2017 ACM Conference on Human Factors in Computing Systems, pp. 472483.

Bardzell, Shaowen, Jeffrey Bardzell, and Sarah Ng. 2017. "Supporting cultures of making: Technology, policy, visions, and myths." In Proceedings of the 2017 ACM Conference on Human Factors in Computing Systems, pp. 6523-6535.

Bijker, Wiebe E., Thomas Parke Hughes, and Trevor J. Pinch, eds. 1987. The social construction of technological systems: New directions in the sociology and history of technology. Cambridge, MA. MIT Press.

Bijker, Wiebe E. 1997. Of bicycles, bakelites, and bulbs: Toward a theory of sociotechnical change. Cambridge, MA. MIT Press.

Bivens Rena and Oliver L. Haimson. 2016. "Baking Gender into Social Media Design: How Platforms Shape Categories for Users and Advertisers." Social Media E Society 2 (2016): 4. 
Callon, Michel. 1998. "An Essay on Framing and Overflowing: Economic Externalities Revisited by Sociology." The Sociological Review 46, no. 1_suppl (1998): 244-269.

Carr, E. Summerson, and Michael Lempert. 2016. "Introduction: Pragmatics of scale." In Scale: Discourse and dimensions of social life: 1-24.

Cartier, Carolyn. 2011. Globalizing South China. Hoboken, NJ. John Wiley \& Sons.

Castells, Manuel. 2011. The rise of the network society. Hoboken, NJ. John Wiley \& Sons.

Chakravartty, Paula, and Sreela Sarkar. 2013. "Entrepreneurial justice: The new spirit of capitalism in emergent India." Popular Communication 11, no. 1 (2013): 58-75.

Chan, Anita Say. 2013. Networking peripheries: Technological futures and the myth of digital universalism. Cambridge, MA. MIT Press.

Collier, S. J. 2011. Post-Soviet social: neoliberalism, social modernity, biopolitics. Princeton University Press. Princeton, NJ.

Dirlik, Arif. 1989. The origins of Chinese communism. Oxford, UK. Oxford University Press.

Dourish, Paul, and Scott D. Mainwaring. 2012. "Ubicomp's colonial impulse." In Proceedings of the 2012 ACM Conference on Ubiquitous Computing, pp. 133-142. ACM.

Easterling, Keller. 2012. "Zone: The spatial softwares of extrastatecraft." Places Journal (2012).

Edwards, Paul N. 1997. The closed world: Computers and the politics of discourse in Cold War America. Cambridge, MA. MIT Press.

Falzon, M.-A. 2009. Multi-sited ethnography: theory, praxis and locality in contemporary research.

Ferguson, James. 2006. “Transnational Topographies of Power.” In Maurer and Schwab (eds)., 7998. Accelerating Possession: Global Futures of Property and Personhood. New York, NY.

Columbia University Press.

Ferguson, James. 2014. "Transnational topographies of power: beyond" the State" and" civil society" in the study of African politics." Occasional paper 19 (2014): 45-71.

Florida, Richard. 2014. The rise of the creative class--revisited: Revised and expanded. Arizona. Basic Books.

Fox, Sarah, Jill Dimond, Lilly Irani, Tad Hirsch, Michael Muller, and Shaowen Bardzell. 2017. "Social Justice and Design: Power and oppression in collaborative systems." In Companion of the 2017 ACM Conference on Computer Supported Cooperative Work and Social Computing, pp. 117-122. ACM.

Gallagher, Mary Elizabeth. 2011. Contagious capitalism: Globalization and the politics of labor in China. Princeton, NJ. Princeton University Press.

Gal, Susan. 2016. "Scale-making: Comparison and perspective as ideological projects." Scale: Discourse and dimensions of social life: 91-111.

Glauber Ann Jeannette, Sarah Moyer, Magda Adriani, and Iwan Gunawan. 2016. The cost of fire: an economic analysis of Indonesia's 2015 fire crisis. Washington, DC. The World Bank.

Goldstein, Jenny E. 2014. "The afterlives of degraded tropical forests: New value for conservation and development." Environment and Society 5, no. 1: 124-140.

Greenhalgh, Susan. 2010. Cultivating Global Citizens: Population in the Rise of China. Cambridge, MA. Harvard University Press.

Haraway, Donna. 2008. When Species Meet. Minneapolis, MN. University of Minnesota Press. 
Haraway, Donna. 1991. Simians, Cyborgs, and Women: The Reinvention of Nature. New York, NY. Routledge.

Haraway, Donna. 1998. "Situated knowledges: The science question in feminism and the privilege of partial perspective." Feminist studies 14, no. 3 (1988): 575-599.

Hecht, Gabrielle. 2012. Being nuclear: Africans and the global uranium trade. Cambridge, MA. MIT Press.

Hecht, Gabrielle. 2018. "Interscalar Vehicles for an African Anthropocene: On Waste, Temporality, and Violence." Cultural Anthropology, 33, 1, (2018) 109-141.

Hyndman, Jennifer. 2001. "Towards a feminist geopolitics." Canadian Geographer/Le Géographe Canadien 45 (2): 210-222.

Irani, Lilly. 2015. "Hackathons and the making of entrepreneurial citizenship." Science, Technology, $\mathcal{E}$ Human Values 40, no. 5 (2015): 799-824.

Irani, Lilly. 2019. Chasing Innovation: Making Entrepreneurial Citizens in Modern India. Princeton University Press.

Irvine, Judith. 2016. "Going upscale: Scales and scale-climbing as ideological projects." In Carr \& Lempert (Eds). 213-232. In Scale: Discourse and dimensions of social life. Oakland, CA. University of California Press.

Knorr Cetina, Karin. 2009. Epistemic cultures: How the sciences make knowledge. Cambridge, MA. Harvard University Press.

Latour, Bruno. 2005. Reassembling the social: An introduction to actor-network-theory. Oxford, UK. Oxford University Press.

Lempert, Michael. 2012. "Interaction rescaled: How monastic debate became a diasporic pedagogy." Anthropology \& Education Quarterly 43, no. 2 (2012): 138-156.

Lin, Cindy, and Andrew Moon. 2016. "Negotiating Time: Design as Historical Practice." PORTAL Journal of Multidisciplinary International Studies 13, no. 2 (2016).

Lindtner, Silvia. 2020. Prototype Nation: China and the Contested Promise of Innovation. Princeton, NJ. Princeton University Press.

Lindtner, Silvia and Seyram Avle. 2017. "Tinkering with Governance: Technopolitics and the Economization of Citizenship." In Proc. of the ACM Conference on Human-Computer Interaction, Vol. 1, CSCW, 70: 1-18.

Marcus, G. E. 1995. "Ethnography in/of the World System: The Emergence of Multi-Sited Ethnography." Annual Review of Anthropology 24: 95-117.

Massey, Doreen. 1993. "Power Geometry and a progressive sense of place. In Bird, Curtis, Putnam, Robertson, and Tickner (eds). 59 - 69. Mapping the futures. Abington, Routledge.

Mitchell, Timothy. 2002. Rule of experts: Egypt, techno-politics, modernity. Oakland, CA. University of California Press.

Neff, Gina. 2012. Venture Labor: Work and the Burden of Risk in Innovative Industries. Cambridge, MA. MIT Press.

O'Donnell, Mary Ann, Winnie Wong, and Jonathan Bach. 2017. Learning from Shenzhen: China's Post- Mao Experiment from Special Zone to Model City. Chicago, IL. University of Chicago Press. 
Ong, Aihwa. 2006. Neoliberalism as Exception: Mutations in Citizenship and Sovereignty. Durham, NC. Duke University Press.

Ong, Aihwa and Donald Nonini, eds. 2003. Ungrounded empires: The cultural politics of modern Chinese transnationalism. Abingdon, UK. Routledge.

Porter, Theodore M. 1996. Trust in numbers: The pursuit of objectivity in science and public life. Princeton, NJ. Princeton University Press

Rajan, K.S., 2006. Biocapital: The constitution of postgenomic life. Durham, NC. Duke University Press.

Radjawali, Irendra, and Oliver Pye. 2015. "Counter-mapping land grabs with community drones in Indonesia." In Proceedings of the Land Grabbing, Conflict and Agrarian-Environmental Transformations: Perspectives from East and Southeast Asia, Chiang Mai, Thailand (2015): 5-6.

Rofel, Lisa. 2007. Desiring China: Experiments in neoliberalism, sexuality, and public culture (2007). Durham, NC. Duke University Press.

Roitman, Janet. 2005. Fiscal disobedience: An anthropology of economic regulation in Central Africa. Princeton, NJ. Princeton University Press.

Rose, Nikolas. 1990. Governing the soul: The shaping of the private self. Taylor \& Frances/Routledge.

Sarkar, Sreela. 2017. "Passionate Producers: Corporate Interventions in Expanding the Promise of the Information Society." Communication, Culture \& Critique 10, no. 2 (2017): 241-260.

Saxenian, AnnaLee. 1996. Regional Advantage: Culture and Competition in Silicon Valley and Route 128. Cambridge, MA. Harvard University Press.

Sims, Christo. 2017. Disruptive fixation: School reform and the pitfalls of techno-idealism. Princeton, NJ. Princeton University Press.

Star, Susan Leigh, and Karen Ruhleder. 1996. "Steps toward an ecology of infrastructure: Design and access for large information spaces." Information systems research 7, no. 1 (1996): 111134.

Terranova, Tiziana. 2000. "Free Labor: Producing Culture for the Digital Economy." Social Text, 18,2 , (2000): 33-58.

Tsing, Anna. 2000. "The global situation." Cultural anthropology 15, no. 3 (2000): 327-360.

Tsing, Anna. 2011. Friction: An Ethnography of Global Connection. Princeton, NJ. Princeton University Press.

Tsing, Anna. 2012. “On Nonscalability: The Living World Is Not Amenable to Precision-Nested Scales." Common Knowledge, 18, 3, (2012): 505-524

Tsing, Anna. 2015. The mushroom at the end of the world: On the possibility of life in capitalist ruins. Princeton, NJ. Princeton University Press.

Tuan, Yi-Fu. 1975. "Place: an experiential perspective." Geographical review (1975): 151-165.

Wallis, Cara. 2013. "Technology and/as Governmentality: The Production of Young Rural Women as Low-Tech Laboring Subjects in China." Communication and Critical/Cultural Studies 10 (4): 341-358. https:/ / doi.org/10.1080/14791420.2013.840386.

Zhang, Amy. 2014. "Rational Resistance: Homeowner contentions against waste incineration in Guangzhou." Special feature: Contested Urban Spaces: Whose right to the city? China Perspectives. 2 (2014): 45-52. 